\title{
Discussion on the Rate Controlling Process of Coarsening of Niobium Carbonitrides in a Niobium Microalloyed Steel
}

\author{
David San Martín ${ }^{1,2, a}$, Francisca G. Caballero ${ }^{1, b}$ Carlos Capdevila $^{1, c}$, and \\ Carlos García de Andrés ${ }^{1, d}$ \\ ${ }^{1}$ Solid-Solid Phase Transformations Group in Steels (GITFES), Department of Physical \\ Metallurgy, Centro Nacional de Investigaciones Metalúrgicas (CENIM), CSIC, Av. Gregorio del \\ Amo 8, 28040, Madrid, Spain. http://www.cenim.csic.es/downloadzone/grupos/gitfes/gitfes es.html \\ ${ }^{2}$ Fundamental of Advance Materials Group, Faculty of Aerospace Engineering, TU Delft, \\ Kluyverweg 1, 2629 HS Delft, The Netherlands. http://www.Ir.tudelft.nl/ fam \\ ad.m.sanmartin@Ir.tudelft.nl, dsm@cenim.csic.es, ${ }^{b}$ fgc@cenim.csic.es, ${ }^{c} \underline{c c m @ c e n i m . c s i c . e s}$, \\ cgda@cenim.csic.es.
}

Keywords: Microalloyed Steel, Austenite Grain Growth, Coarsening of Carbonitrides

\begin{abstract}
Austenite grain growth in microalloyed steels is governed by the coarsening of fine precipitates present at grain boundaries below the grain coarsening temperature. Zener model is widely used in metals to describe the pinning effect of second phase particles precipitated in the matrix. In this work it has been discussed whether grain boundary or volume diffusion is the rate controlling process for the coarsening of the niobium carbonitrides. Calculations on austenite grain growth kinetics, obtained coupling Zener theory and both rate controlling processes of precipitate coarsening, have been compared against experimental austenite grain size results under nonisothermal heating conditions. In this sense, it has been concluded that the coarsening of niobium carbonitrides is mainly controlled by volume diffusion of $\mathrm{Nb}$ in austenite.
\end{abstract}

\section{Introduction}

The driving force for grain growth results from the decrease in free energy of the system. The grain boundary area is the main source of energy for grain growth process; therefore, the system will evolve to reduce its grain boundary area [1]. Larger grains will grow at the expense of the smaller ones. Microalloying elements like vanadium, niobium and titanium have been employed in the past two decades to produce fine precipitation in the matrix. The austenite grain boundaries and dislocations are pinned by these precipitates, inhibiting their movement during the thermomechanical processing of steels [2].

Zener [3] was the first to obtain a quantitative theoretical expression to evaluate the influence of precipitate inhibiting effect on grain boundary motion. Other authors [4-12] have given similar expressions since the seminal work by Zener. Although these models are based on a number of physical and geometric assumptions that differ among the models, all of them can be generalized using the following general equation,

$$
\bar{D}_{c r i t}=\phi \frac{r}{f^{n}} \text {. }
$$

Where $\bar{D}_{\text {crit }}$ is the average critical 3-D prior austenite grain size (3DPAGS), $r$ and $f$ are the mean radius and volume fraction of carbonitrides, respectively, and $\phi$ depends on factors such as the 
geometry of precipitates and austenite grains or coherency between precipitate and matrix. The value of $n$ depends on the distribution of precipitates in the matrix. The assumption of random distribution leads to $n=1$ (Zener original model), whereas preferential distribution of precipitates at grain boundaries leads to $\mathrm{n}<1$ [13].

The present article describes the austenite grain growth during a continuous heating at different rates in a niobium microalloyed steel. A set of expressions is proposed to describe the austenite growth kinetics under the influence of pinning precipitates during a continuous heating at a constant rate. It will be discussed about the randomness of the distribution of carbonitrides in the matrix and whether volume diffusion or grain boundary diffusion of niobium is the rate controlling process for the coarsening of precipitates.

\section{Materials and experimental procedure}

A low-carbon niobium microalloyed steel has been studied. Its chemical composition is listed in Table 1.

Table 1 Chemical composition [mass\%]

\begin{tabular}{llllllllllll}
\hline $\mathrm{C}$ & $\mathrm{Mn}$ & $\mathrm{Si}$ & $\mathrm{S}$ & $\mathrm{P}$ & $\mathrm{Nb}$ & $\mathrm{Cu}$ & $\mathrm{Cr}$ & $\mathrm{Ni}$ & $\mathrm{Mo}$ & $\mathrm{Al}$ & $\mathrm{N}$ \\
\hline
\end{tabular}

\begin{tabular}{llllllllllll}
0.11 & 1.47 & 0.27 & 0.013 & 0.015 & 0.031 & 0.011 & 0.03 & 0.03 & 0.006 & 0.039 & 0.0051 \\
\hline
\end{tabular}

Cylindrical samples of $3 \mathrm{~mm}$ in diameter and $12 \mathrm{~mm}$ in length were used to reveal grain boundaries by the thermal etching method $[14,15]$. Samples were austenitized in vacuum $(>1 \mathrm{~Pa})$ at three different heating rates, $\operatorname{HR}(0.05,0.5,5 \mathrm{~K} / \mathrm{s})$ and at temperatures ranging from $1183 \mathrm{~K}$ to $1523 \mathrm{~K}$ (T $\gamma)$ and subsequently cooled down to room temperature at $1 \mathrm{~K} / \mathrm{s}$. This way, prior austenite grain boundaries are revealed without chemical etching.

The average austenite grain size in 2-D, $\bar{A}$, was measured using an image analyser. In this work it will be considered that the 3-D prior austenite grains as tetrakaidecahedrons. Based on the work by Hull and Houk [16] the following expression will be used to calculated the 3DPAGS can be given,

$\bar{D}=1.447 \sqrt{A}$.

A two-step extraction carbon replica method has been used to examine and identify precipitates present in the austenite grain boundaries [17]. Carbon replicas obtained using this method where examined using a Jeol Jem $2010 \mathrm{TEM}$, at an operating voltage of $200 \mathrm{kV}$, with an energy dispersive spectroscopic (EDS) analyser Oxford Inca.

\section{Results and Discussion}

Figure 1 shows the evolution of the 3DPAGS during a continuous heating at $0.05,0.5$ and $5 \mathrm{~K} / \mathrm{s}$. Fig. 2 shows the prior austenite microstructure formed after heating the sample to three different temperatures at a rate of $5 \mathrm{~K} / \mathrm{s}$.

Carbon replicas showed that niobium carbonitrides were precipitated in the matrix (Fig. 3). ' $\mathrm{Cu}$ ' peaks in the EDS spectrum corresponds to the copper mesh that supports the replica. The average radius for carbonitrides measured from carbon replicas just above $A c_{3}$ temperature was $r_{0}=0.01 \mu \mathrm{m}$. $A c_{3}$ is the temperature at which the process of austenitization is completed and it was experimentally determined for this steel at $1168 \pm 3 \mathrm{~K}$ when heating at $0.05 \mathrm{~K} / \mathrm{s}$ [18]. 


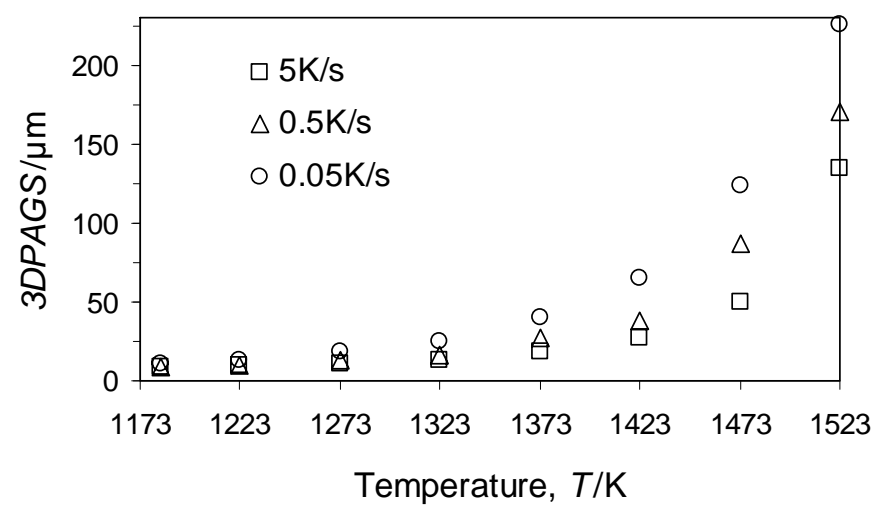

Fig. 1 Evolution of the 3-D prior austenite grain size (3DPAGS) for three different heating rates.
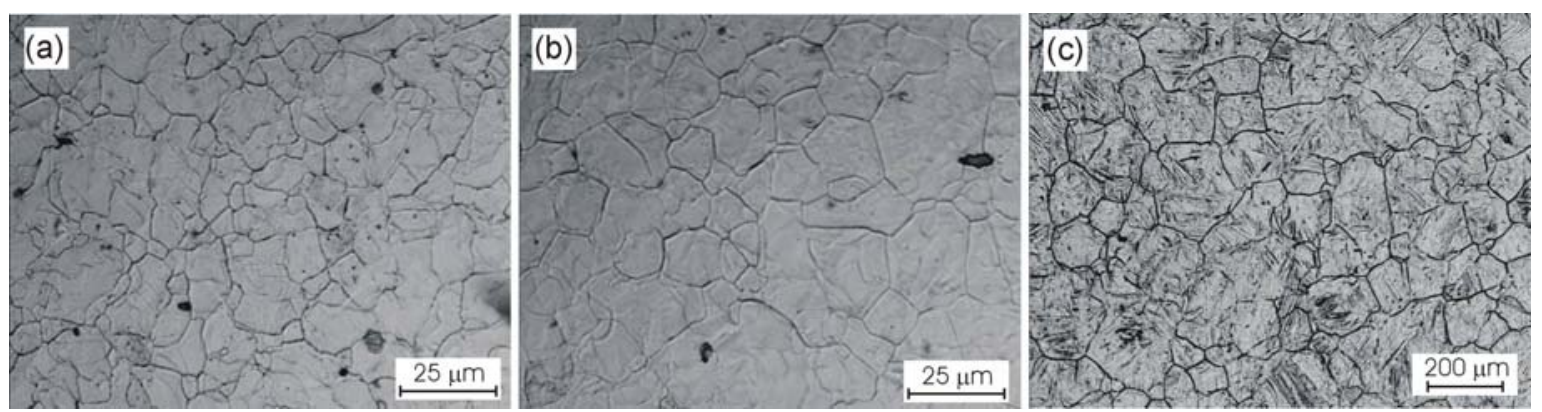

Fig. 2 Prior austenite microstructure obtained after heating at 5K/s; (a) 1323K, (b) 1423K and (c) $1523 \mathrm{~K}$.

It is well known that the $3 D P A G S$ in plain carbon steels increases exponentially with temperature [19]. However, in microalloyed steels it is usual to observe two-step grain growth [19-22]. The sluggish grain growth in the lower range of temperatures (first step) is associated with the existence of precipitates that pin the boundaries, inhibiting their movement. As temperature is raised, several precipitates dissolve while others coarsen. Thus, some grain boundaries are free to move and the average $3 D P A G S$ of the microstructure will grow [21-23].
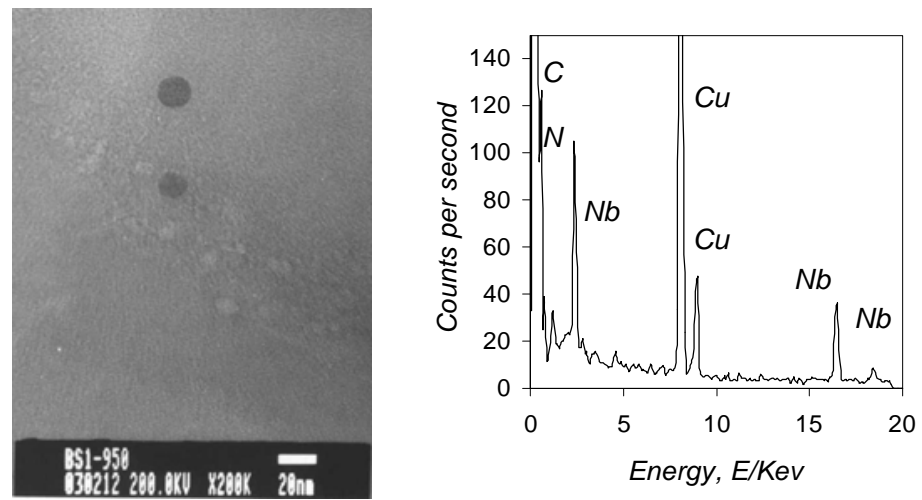

Fig. 3 Niobium carbonitride present in the austenitic matrix.

In microalloyed steels, although the limits between both steps of growth are not clearly divorced, the grain coarsening temperature $\left(T_{G C}\right)$ is usually referred to as the temperature that separates both steps of growth $[20,23]$. As it was discussed elsewhere [24], the $T_{G C}$ in this steel for heating rates $0.05,0.5,5^{\circ} \mathrm{C} / \mathrm{s}$ are 1363,1385 and $1393 \mathrm{~K}$, respectively. 
At sufficiently high heating temperatures, the niobium carbonitrides precipitated in the matrix become unstable. Dissolution of some of the carbonitrides begins in order to reach the equilibrium amount of niobium in solid solution in austenite, as predicted by the solubility product of the niobium carbonitrides [23], at the corresponding temperature,

$$
\log K s=\log [N b][C+(12 / 14) N]=2.26-(6770 / T) .
$$

Where $N b, C$ and $N$ refer to niobium, carbon and nitrogen in solid solution in austenite, respectively, in mass-\%; Ks is the solubility product, and $T$ is temperature in $\mathrm{K}$.

As temperature is increased, more carbonitrides will dissolve and the volume fraction of these precipitates will decrease until the $T_{D I S S}$ is attained. At this temperature all precipitates will be dissolved and all the $\mathrm{Nb}, \mathrm{C}$ and $N$ will be in solid solution in the austenitic matrix. According to Eq. (3), for the present steel, $T_{D I S S}=1437 \mathrm{~K}$. Considering mass balance of niobium and carbon equivalent and the stoichiometric relation between these elements, the amount of niobium precipitated as carbonitrides, the niobium in solid solution in equilibrium with austenite and the volume fraction of precipitates can be determined [24].

Some experimental works have shown that during heating, precipitates that remain undissolved in the matrix have a tendency to coarsen at the expense of the smaller ones $[19,22,25]$. The driving force for this process is provided by the consequent reduction in the total interfacial energy. These authors $[19,22,25]$ experimentally showed that the higher the heating temperature, the coarser the niobium carbonitrides were, although less volume fraction of them were precipitated in the matrix. Other authors [26] have observed that for heating temperatures lower than the $T_{D I S S}$, coarsening of precipitates was taking place; while for heating temperatures higher than $T_{D I S S}$, only dissolution occurred.

Depending on the rate controlling process, the law that describes the coarsening of carbonitrides varies. The diffusivity of niobium is much lower than the diffusivity of carbon or nitrogen in austenite; hence, niobium diffusion is supposed to be the rate controlling process during ripening of carbonitrides. If most precipitates are located preferentially at grain boundaries, it is expected that during coarsening, most of the niobium in solid solution will diffuse along grain boundaries. In this case, according to Ardell [27] the variation of mean radius of grain boundary precipitates with time is described by the following expression,

$$
r^{3} \frac{d r}{d t}=\frac{2 \sigma[N b] \delta D_{G B} V_{m}}{3 v G R T}
$$

Where $r$ is the radius of carbonitrides in microns, $T$ is the absolute temperature, $t$ is time in seconds, $\sigma$ is the interfacial energy per unit area between precipitate and matrix $\left(0.5 \times 10^{-12} \mathrm{~J}_{\mu m^{-2}}\right)$ [28], $\delta$ is the width of the grain boundary $\left(10^{-3} \mu \mathrm{m}\right)$ [29], $V_{m}$ is the molar volume of carbonitrides $\left(1.28 \times 10^{13}\right.$

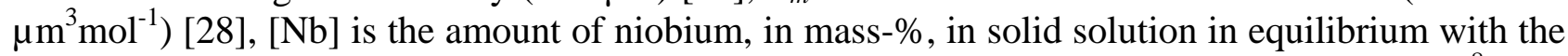
austenite matrix, and $D_{G B}$ is the coefficient of niobium diffusion in grain boundaries $\left(9.3 \times 10^{8} \exp (-\right.$ 162203/RT) $\mu^{2} \mathrm{~s}^{-1}$ ) [30]. It has been considered that the activation energy for niobium grain boundary diffusion is $Q_{G B}=Q_{V} / 1.8$, where $Q_{V}$ is the activation energy for niobium volume diffusion [30]. Parameter $v$ has been determined by Ardell [27] and varies rapidly for small values of the volume fraction of carbonitrides. Parameter $R\left(8.31 \mathrm{JK}^{-1} \mathrm{~mol}^{-1}\right)$ is the universal gas constant and $G$ is a geometrical constant characteristic of a given system [27].

During a continuous heating, the heating curve can be expressed as a series of isothermal steps that occur at consecutively increasing temperatures. In this sense, the total increase in the radius of carbonitrides during heating can be computed as the sum of the partial contributions at each heating temperature (step). The heating time at each step, can be expressed as a function of the heating rate $d t=d T / \theta$, where $\theta$ is the heating rate and $d T$ is the increment in temperature between two successive 
steps. In the limit where $d T \rightarrow 0$, the sum of consecutive steps can be simplified integrating in the whole range of temperatures $\left[A c_{3}, T\right]$. Therefore, the radius of niobium carbonitrides during heating can be written as,

$r^{4}=r_{0}^{4}+\frac{8 \sigma \delta V_{m}}{3 G R \theta} \int_{A_{c 3}}^{T} \frac{[N b] D_{G B}}{v T} d T$

Where $r_{0}(0.01 \mu \mathrm{m})$ is the radius of precipitates at the end of austenite formation. On the other hand, if precipitates are distributed in austenite at random, due to the low volume fraction of the sample occupied by the grain boundaries, the number of precipitates present in the matrix will be higher than those located at grain boundaries. In this case, most of niobium in solid solution will diffuse through the volume of the austenitic matrix in order to contribute to the coarsening of niobium carbonitrides located at grain boundaries. In this case, according to the theory by Lifshitz and Slyozov [31], precipitate coarsening is controlled by niobium volume difusión. An equivalent expression to Eq. (5) can be obtained,

$r^{3}=r_{0}^{3}+\frac{4 \sigma V_{m}}{9 R \theta} \int_{A_{c 3}}^{T} \frac{[N b] D_{V}}{T} d T$.

Where $D_{V}$ is the coefficient of niobium volume difusión $\left(9.3 \times 10^{8} \exp (-291966 / \mathrm{RT}) \mu^{2} \mathrm{~s}^{-1}\right)$ [30]. The other parameters in Eq. (6) have been defined previously.

In Fig. 4a and Fig. 4b the evolution of the radius of niobium carbonitrides with temperature and heating rate has been represented as predicted by Eq. (5) and (6), respectively. As it would be expected, Fig. 4 shows that the coarsening of carbonitrides controlled by niobium grain boundary diffusion is much faster than coarsening governed by niobium volume diffusion.
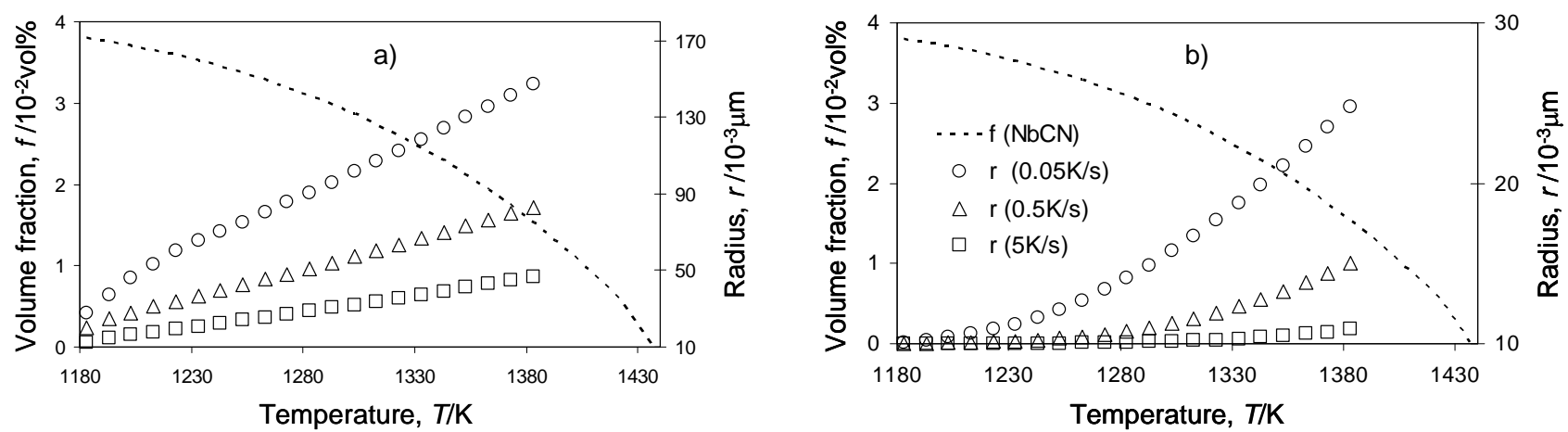

Fig. 4 Evolution of the radius of niobium carbonitrides with heating rate and temperature under two different assumptions: a) coarsening controlled by niobium grain boundary diffusion and b) controlled by niobium volume diffusion. Evolution of the equilibrium volume fraction of carbonitrides is also shown (dashed line).

As it was pointed out in the introduction of this work, all models concerning the growth of grains under the influence of a dispersed second phase can be generalized using Eq. (1). According to this equation, the limiting grain size critically depends on the assumptions regarding the randomness of the boundary particle correlations (value of $n$ ). Following the works by Doherty et al. [32], and Anand and Gurland [33], if most of the particles were located at grain boundaries, $n=1 / 2$. On the other hand, as originally proposed by Zener [3], and also shown by several authors [4,11], the assumption of random intersection between grain boundaries and second phase particles leads to $n=1$ in Eq. (1). 
Therefore, depending on the distribution of precipitates in the matrix, two different models should be used in the calculations. In Fig. 5a-b results obtained using the two models have been represented assuming that the equilibrium volume fraction of carbonitrides, $f$, and the equilibrium content of niobium in solid solution, $[\mathrm{Nb}]$, are reached at each austenitization temperature for a heating rate of $0.05 \mathrm{~K} / \mathrm{s}$. Thus, Eq. (1) is only valid for temperatures lower than the $T_{G C}$ temperature [24]. Fig. 5a shows that coarsening of precipitates due to grain boundary diffusion predicts much faster grain growth kinetics than the growth measured experimentally. Results show that grain growth under the influence of precipitates that are pinning grain boundaries is best modeled assuming that precipitates are distributed at random in the microstructure and that the process controlling the coarsening of precipitates is the niobium volume diffusion. These results are in agreement with the results of other authors concerning the modelling of austenite grain growth under the influence of carbonitrides [25,34-37].
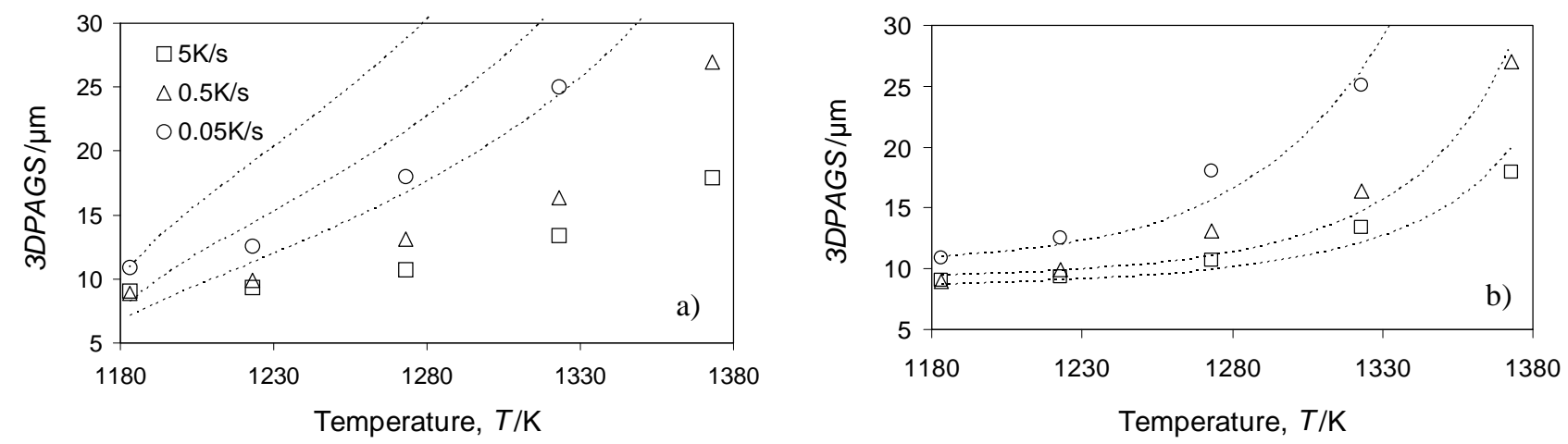

Fig. 5 Evolution of the experimental (open points) and theoretical (dot lines) values of $\bar{D}_{\text {crit }}$ during a continuous heating according to the predictions of two different models: a) most precipitates located at grain boundaries, coarsening of precipitates governed by niobium grain boundary diffusion; b) precipitates randomly located in the matrix, coarsening of precipitates mainly governed by niobium volume diffusion.

\section{Summary}

The austenite grain coarsening under the influence of pinning precipitates during a continuous heating at a constant rate has been studied. It has been found that austenite grain growth under the influence of niobium carbonitrides is best described under the assumption of random distribution of precipitates in the austenitic matrix and that coarsening of precipitates is mainly controlled by niobium volume diffusion.

\section{Acknowledgement}

The authors acknowledge financial support from Spanish Ministerio de Ciencia y Tecnología (Project MAT2000-0412-P4-02). F.G. Caballero would like to thank Spanish Ministerio de Ciencia y Tecnología for the financial support in the form of a Ramón y Cajal contract (Programa RyC 2002).

\section{References}

[1] H.V. Atkinson: Acta Metall. Vol. 36 (1988) p. 469. 
[2] N.T. Baker: Future Developments of Metals and Ceramics, edited by J.A. Charles, G.W. Greenwood and G.C. Smith (Institute of Materials, London 1992), p. 75.

[3] C. Zener, quoted by C. S. Smith: Trans. AIME Vol. 175 (1948) p. 15.

[4] M. Hillert: Acta Metall Vol. 13 (1965) p. 227.

[5] T. Gladman: Proceedings of the Royal Society Vol. 294A (1966) p. 298.

[6] N. A. Haroun and D. W. Budworth: J. Mater. Sci Vol. 3 (1968) p. 326.

[7] N. A. Haroun: J. Mater. Sci Vol. 15 (1980) p. 2816.

[8] P. Hellman and M. Hillert: Scand. J. Metall. Vol. 4 (1975) p. 211.

[9] N. Ryum, O. Hunderi and E. Nes: Scr. Metall Vol. 17 (1983) p. 1281.

[10] E. Nes, N. Ryum and O. Hunderi: Acta Metall Vol. 33 (1985) p. 11.

[11] P.R. Rios: Acta Metall. Vol. 35 (1987) p. 2805.

[12] Y. Ogino: Tetsu-to-Hagane Vol. 57 (1971) p. 533.

[13] Y. Liu and B. R. Patterson, Acta Mater Vol. 44 (1996) p. 4327.

[14] C. García de Andrés, M. J. Bartolomé, C. Capdevila, D. San Martín, F. G. Caballero, V. López: Mater. Charact. Vol. 46 (2001) p. 389.

[15] C. García de Andrés, F.G. Caballero, C. Capdevila, D. San Martín: Mater. Charact. Vol. 4 (2003) p. 121.

[16] F. C. Hull and W. J. Houk: J. Met. April (1953) p. 565.

[17] A. Fukami: Jeol News, July (1967) 5.

[18] D. San Martín: Modelización de la cinética de austenización y crecimiento de grano austenítico en aceros ferrítico-perlíticos, PhD Thesis, (Universidad Complutense of Madrid, Spain 2003) p.159.

[19] R. Coladas, J. Masounave, G. Guérin and J.-P.Bailón: Met. Sci. November (1977) p. 509.

[20] L.J. Cuddy and J. C. Raley: Metall. Trans. A Vol. 14 (1983) 1989.

[21] F. Peñalba, C. García de Andrés, M. Carsí, F. Zapirain: J. Mater. Sci. Vol.31 (1996) p. 3847.

[22] T. Gladman and F. B. Pickering: J. Iron Steel Inst. Vol. 205 (1967) p. 653.

[23] E.J. Palmiere, C.I. Garcia and A.J. DeArdo: Metall. Mater. Trans. A Vol. 25 (1994) p. 277.

[24] D. San Martin, F.G. Caballero, C. Capdevila and C. Garcia de Andres, Mater Trans. Vol. 45 (2004) p. 2797.

[25] E. Anelli, M. Paolicchi and G. Quintiliani, Private Communication.

[26] L.M. Cheng, E.B. Hawbolt and T.R. Meadowcroft, Can. Metall. Quart. Vol.39 (2000) p.73.

[27] A. J. Ardell, Acta Metall. Vol. 20 (1972) p. 601.

[28] B. Dutta, E. Valdés, C.M. Sellars: Acta Metall. Mater. Vol. 40 (1992) p. 653.

[29] H.S. Zurob, C.R. Hutchinson, Y. Brechet and G. Purdy: Acta Mater. Vol. 49 (2001) p. 4183.

[30] J. Fridberg, L. E. Törndahl and M. Hillert, Jernkont. Ann, Vol. 153 (1969), p. 263.

[31] I.M. Lifshitz and V.V. Slyozov: J. Phys. Chem. Solids Vol. 19 (1961) p. 35. 
[32] R. D. Doherty, D. J. Srolovitz, A. D. Rollet and M. P. Anderson, Scripta Metall. Vol. 21 (1987) p. 675.

[33] L. Anand and J. Gurland, Metall. Trans. A Vol. 6 (1975) p. 928.

[34] T. Siwecki, S. Zajac and Goran Engberg, Proceedings of the 37th Mechanical Working and Steel Processing Conference (1996) p. 721.

[35] T. Gladman: Iron and Steelmaking Vol. 16 (1989) 241-245

[36] N. E. Hannerz and F. de Kazinczy: J. Iron and Steel Inst. May (1970) p. 475.

[37] P. A. Manohar, D.P. Dunne, T. Chandra and C.R. Killmore: ISIJ Int. Vol. 36 (1996) p. 194. 